\title{
Phosphorus bioavailability in anoxic marine systems: Vivianite solubility revisited
}

\author{
MATTHEW P. BRADY ${ }^{1}$, ROSALIE TOSTEVIN ${ }^{2}$ AND \\ NICHOLAS J. TOSCA ${ }^{1}$
}

${ }^{1}$ University of Cambridge

${ }^{2}$ University of Cape Town

Presenting Author: mpb68@cam.ac.uk

In order to maintain the low $\mathrm{pO}_{2}$ concentrations that apparently characterised much of the Proterozoic, recent models have suggested that $\mathrm{Fe}(\mathrm{II})$-phosphate precipitation would have limited phosphate availability in dominantly anoxic and ferruginous oceans, in turn attenuating net primary production (NPP) and organic carbon burial. Nevertheless, the solubility of vivianite has not been quantified in marine systems, and thermodynamic data used to underpin biogeochemical models rests on solubility determinations made across a limited $\mathrm{pH}$ range ( 4.7-5.6), neglecting important shifts in dissolved phosphate speciation and solubility.

Here we experimentally determine vivianite solubility in synthetic seawater solutions at $25^{\circ} \mathrm{C}$ as a function of salinity and $\mathrm{pH}$. Our data, together with previously determined vivianite solubility measurements, reveals an approximate 1000-fold increase in the apparent solubility of vivianite between $\mathrm{pH} 4$ and 8.5. In order to determine a consistent value for vivianite solubility $\left(\mathrm{K}_{\mathrm{sp}}\right)$ across a range of aquatic conditions, new and existing data were used to develop and optimise a Pitzer ion interaction-based thermodynamic model including aqueous $\mathrm{Fe}$ phosphate complexation. Together, our model closely reproduces measured stoichiometric dissociation constants of phosphoric acid in seawater media as a function of salinity, and predicts a strong salinity control on vivianite saturation (arising from aqueous $\mathrm{Ca}$ - and $\mathrm{Mg}$-phosphate complexation in seawater), consistent with an apparent locus of vivianite deposition in brackish and lacustrine systems. Application of our model to published modern marine pore water datasets reveals that pore waters are poised precisely at equilibrium vivianite solubility through depth intervals where vivianite has been unambiguously identified. More broadly, if vivianite solubility buffered deep marine phosphate concentrations in anoxic Proterozoic marine systems, our model predicts that total phosphate concentrations would have been approximately three orders of magnitude higher than previously estimated. This prompts a re-evaluation of the mechanisms that facilitated low $\mathrm{pO}_{2}$ through much of the Proterozoic, and defines parameter space where $\mathrm{Fe}^{2+}$ would not have acted as a sink for dissolved phosphate, alleviating a key problem in several recent prebiotic chemical scenarios. 